\title{
COTRADUZINDO A POESIA TRANSMENTAL RUSSA DE VELIMIR KHLÉBNIKOV
}

\author{
Mário Ramos Francisco Júnior ${ }^{1}$ \\ 1-Universidade de São Paulo, São Paulo, São Paulo, Brasil
}

\begin{abstract}
Resumo: Este artigo tem por objetivo analisar as traduções de poemas zaúm do poeta cubofuturista russo Velimir Khlébnikov. Um dos mais influentes poetas russos da primeira metade do século XX, Khlébnikov utilizou e desenvolveu, em sua obra, diversos experimentos com a linguagem presentes em vários manifestos das vanguardas russas. A língua zaúm ou transmental foi traduzida pela primeira vez na coletânea de poemas $P o$ esia Russa Moderna, de 1968. A retradução é considerada, neste artigo, como um processo de diálogo, que preferimos chamar de cotradução, com o aproveitamento e reelaboração dos recursos recriados por Augusto e Haroldo de Campos e Bóris Schnaiderman em língua portuguesa.

Palavras-chave: Poesia Russa; Tradução; Velimir Khlébnikov
\end{abstract}

\section{CO-TRANSLATING VELIMIR KHLEBNIKOV'S RUSSIAN TRANSRATIONAL POETRY}

\begin{abstract}
This paper aims to analyze the translations of zaum poems by the Russian Cubo-futurist poet Velimir Khlebnikov. One of the most influential Russian poets of the first half of the twentieth century, Khlebnikov resorted to and developed across his work a number of experiments with the innovative language found in several manifestos of the Russian avant-garde. The zaum - or transrational - language was first translated and published in the 1968 anthology of poems, Modern Russian Poetry. The re-translation is regarded in this paper as a dialogic process, which we view as a co-translation, by making use of and re-elaborating the material once translated by Augusto and Haroldo de Campos and Boris Schnaiderman to the Portuguese language.
\end{abstract}

Keywords: Russian Poetry; Translation; Velimir Khlebnikov. 


\title{
КОПЕРЕВОД РОССИЙСКОЙ ЗАУМСКОЙ ПОЭЗИИ ВЕЛИМИРА ХЛЕБНИКОВА
}

\begin{abstract}
Абстракт: Цель данной статьи - проанализировать переводы поэм заума русского поэта-кубофутуриста Велимира Хлебникова. Хлебников, один из самых влиятельных русских поэтов первой половины двадцатого века, прибегнул к своим работам и разработал ряд экспериментов с инновационным языком, обнаруженным в нескольких манифестах русского авангарда. Заум - или трансрациональный - язык был впервые переведен и опубликован в сборнике стихов Современная Русская Поэзия 1968 года. Повторный перевод рассматривается в этой статье как диалогический процесс, который мы рассматриваем как коперевод, используя и перерабатывая материал, когда-то переведенный Аугусто, Гарольдо де Кампосом и Борисом Шнайдерманом на португальский язык.
\end{abstract}

Ключевые слова: Русская поэзия; Перевод; Велимир Хлебников.

A obra do poeta cubofuturista russo Velimir Khlébnikov (18851922) somente passou a ser conhecida no Brasil a partir de 1968 , com a publicação da primeira edição da coletânea de poemas de vários autores intitulada Poesia Russa Moderna, com traduções de poemas de Khlébnikov, V. Maiakóvski, A. Blok, O. Mandelstam e outros, por Augusto e Haroldo de Campos e Bóris Schnaiderman. Cobrindo um período de produção que vai do Simbolismo do início do século XX à poesia soviética pós-Stálin, a coletânea é, até hoje, a mais importante compilação de poesia russa no Brasil. Até aquele momento, falar em vanguardas russas, entre nós, praticamente resumia-se a falar da poesia de Vladimir Maiakóvski. Significa dizer que, grosso modo, a mais importante experimentação poética das vanguardas russas, a criação da chamada língua zaúm ${ }^{1}$ ou transmental, chegou ao leitor brasileiro também somente com a divulgação dessas traduções. Maiakóvski, apesar de ser considerado

1 A palavra é um neologismo composto pela preposição russa "za" ( $а$ : por, através de, além de, trans) e o substantivo "um” ( $y_{M}$ : mente, inteligência), assim, "transmental".

Cad. Trad., Florianópolis, v. 39, nº esp., p. 330-347, set-dez, 2019 
o "líder" do movimento cubofuturista, à parte o uso de neologismos, nunca fora, de fato, um poeta zaúm.

O núcleo duro do movimento, aquele que projetava e desenvolvia as inovações que constituiriam as bases da língua zaúm a partir dos primeiros manifestos das vanguardas russas, era formado por Velimir Khlébnikov, Alekséi Krutchônikh, David Burliuk e Elena Guro (a última, considerada por muitos dos poetas como a primeira poeta zaúm do grupo). Maiakóvski sempre esteve presente, como poeta, ilustrador, dramaturgo, ator e, principalmente, agitador das vanguardas. E é o próprio Maiakóvski quem vai considerar Khlébnikov "como um dos nossos mestres em poesia e como o magnífico e honestíssimo paladino de nossa luta poética" (Maiakóvski 156). Khlébnikov era aquele que levaria ao limite os experimentos com a linguagem e que faria deles o grande diferencial estético em relação às outras vanguardas que surgiam no contexto europeu.

Os fundamentos da língua zaúm como procedimento poético foram divulgados paulatinamente pelo grupo, manifesto após manifesto, até serem consolidados na "Declaração da Língua Transmental”, assinado por Alekséi Krutchônikh, em 1921. Torna-se necessário destacar aqui alguns itens do manifesto, para melhor compreensão dos métodos e funções da língua transmental, no âmbito da criação poética:

[...] [o pensamento] é livre para exprimir-se recorrendo não somente à língua comum (ou dos conceitos) mas também a uma língua pessoal (o criador é indivíduo) e a uma língua privada de significado determinado, $[\ldots]$ transmental.

[...]

4) Recorre-se à língua transmental:

a) o artista fornece imagens ainda não completamente definidas;

b) quando não se quer designar o objeto, mas apenas aludir a ele através de uma caracterização transmental: 'ele é um tipo assim-assim, possui uma alma quadrangular'. Eis como palavras comuns são usadas em sentido transmental 
$[\ldots]$

c) quando se perde a razão (ódio, ciúme, furor[...]);

d) quando não há necessidade da razão: êxtase místico, amor $[\ldots]$;

6) [...] I. Transmental: a) cantos mágicos, exorcismos, encantamentos; b) 'revelação' (pelo nome ou imagem) de coisa invisível - misticismo; c) criação verbal fonético-musical. (Menezes 30-31)

Acrescentamos alguns pontos bastante relevantes do manifesto "Sadok Sudiéi II" (em português, "Armadilha para Juízes", de 1913, assinado por Krutchônikh, David Burliuk, Nikolai Burliuk, Elena Guro, Vladimir Maiakóvski, Ekaterina Nizen e Velimir Khlébnikov:

1) Soltamos a sintaxe. Começamos a ver nas letras os únicos determinantes da fala. Não respeitamos mais a gramática, na formação e na pronúncia das palavras;

2) Começamos a atribuir significado às palavras, de acordo com suas características gráficas e fônicas;

3) O rol dos prefixos e sufixos tornou-se claro para nós;

4) Rejeitamos a ortografia;

[...]

6) Abolimos a pontuação;

7) Vogais são espaço e tempo. Consoantes são cor, som e cheiro;

8) Demolimos os ritmos [...];

[...]

10) Consideramos a palavra uma criadora do mito; uma palavra, quando morre, dá origem a um mito, e vice-versa. (Krutchônikh, tradução do autor)

Alguns dos aspectos expostos nos manifestos lançam os poemas transmentais na esfera da poesia fonética, muitas vezes quase que destituída de sentido. Talvez esse salto em direção ao vácuo 
na relação entre significado e significante tenha chamado tanto a atenção de muitos estudiosos, no decorrer do século $\mathrm{XX}$, a ponto de se tornar a alcunha "linguagem destituída de sentido" um rótulo frequente aplicado à língua transmental. Assim, para muitos tradutores desses poetas, em diversas línguas, restou a opção da simples transliteração dos poemas, com a reprodução fonética na língua de chegada. Porém, os recursos fonéticos foram apenas um dos métodos de criação zaúm.

O desenvolvimento da língua transmental, principalmente no campo da poesia, com base em pressupostos presentes já nos primeiros manifestos, resultou em outros métodos, entre eles a criação de neologismos, com a utilização das características morfológicas da própria língua russa, e mesmo a possibilidade de contato entre o russo e outras línguas (o persa, línguas africanas, línguas orientais e outras), ou alterações de ordem sintática, também com o aproveitamento de traços específicos do russo, de outras línguas eslavas, ou até das raízes mais remotas de formação dessas línguas. Não seria exagero afirmar que muitos dos poetas, com destaque para Khlébnikov e Krutchônikh, para alimentar sua criação artística, realizavam estudos e produziam ensaios que beiravam a pesquisa em linguística.

No caso específico de Khlébnikov, a diversidade de recursos utilizados soma-se ao grau de inovação proposto em relação a quase tudo o que havia sido feito, em poesia, até sua época, na Rússia ou em outros países, como aponta Boris Schnaiderman no prefácio a Poesia Russa Moderna:

Revolucionando o uso da palavra, Khlébnikov estudou as possibilidades novas de seu emprego. A 'língua transmental' (zaúm) era para ele algo bem concreto e preciso; os sons aglutinados não eram fortuitos, embora estivessem desligados do conceito habitual. A linguagem dos feiticeiros, dos xamãs da Ásia Central; a montagem e desmontagem de palavras; a transformação de nomes próprios em verbos, de substantivos em adjetivos e vice-versa; o re- 
gistro do canto dos pássaros; a formação de palavras nas línguas eslavas em geral - eis alguns dos recursos de que se serviu. Muito antes do surrealismo, já prenunciava a escrita automática. Superando as limitações de espaço e tempo, antecipou em certo sentido o dadaísmo. Seus caligramas são anteriores aos de Apollinaire, e suas montagens de palavras efetuam-se na mesma época que as de Joyce, conforme foi particularmente sublinhado por Benjamin Goriély. (Campos; Campos and Schnaiderman 22)

O que Schnaiderman chama aqui de "montagem e desmontagem de palavras", ou de transformações entre classes de palavras (com o acréscimo de aglutinação de diferentes raízes de palavras, formando novas palavras-conceito, ou atingindo a criação de novos sentidos assemelhados aos obtidos em ideogramas), pode ser bem exemplificado na tradução do poema "Encantação pelo Riso", traduzido por Haroldo de Campos. Nele, o poeta mobiliza as capacidades morfológicas da própria língua, inserindo prefixos e sufixos inusitados e não-convencionais à raiz do substantivo smiékh (смех, "riso"), formando uma série de neologismos de efeito entonacional encantatório, numa derrisão que parte da função do riso na cultura, para chegar à derrisão iconoclasta da própria estrutura morfológica da língua russa:

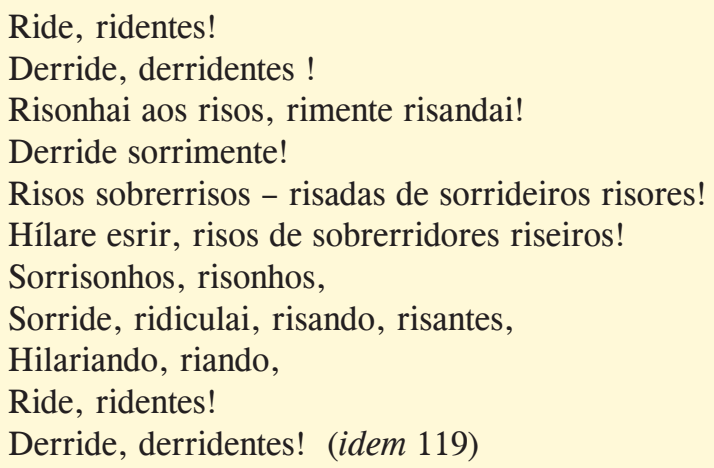


Haroldo de Campos mantém o método de expansão dos sentidos de Khlébnikov, tomando como centros do grupo de neologismos o substantivo "riso" e o verbo "rir" e mobilizando prefixos e sufixos adequados em língua portuguesa ("risonhai, rimente, sobrerridores"), ou aglutinando palavras de diferentes raízes ("derridentes, sorrisonhos"), o que permite alcançar, no conjunto, a ampliação das possibilidades de sentido dos grupos lexicais em contato. O tradutor, fiel ao jogo de perdas e ganhos intrínseco à tradução criativa, toma como princípio de construção do poema a criação de neologismos, e liberta as amarras das classes de palavras e dos campos lexicais agregados e escolhidos em língua portuguesa. Mas o primor técnico, em tradução poética, deve ser sempre acompanhado do aspecto, talvez subjetivo, do efeito que o poema provoca na língua de chegada, e Haroldo de Campos obtém este "tom" khlebnikoviano em nossa língua, como já havia logrado em suas traduções de Maiakóvski, que tanto impressionaram o linguista russo Roman Jakobson, em sua visita a São Paulo em 1968, conseguindo "fazer o português cantar com sotaque russo, a ponto de um russo como Jakobson encontrar no texto traduzido o som de sua língua-mãe", como relata Boris Schnaiderman (Schnaiderman 2011). Assim, as traduções pioneiras dos cerca de vinte poemas de Khlébnikov e outros poemas zaúm de diversos poetas ligados ao movimento cubofuturista, em Poesia Russa Moderna, abriram um vasto campo de trabalho aos tradutores interessados em verter os experimentos zaúm de forma criativa para a língua portuguesa e inauguraram, é possível afirmar, uma "tradição" que alia técnica e percepção poética na transposição entre as duas línguas.

Em termos de quantidade de material traduzido em língua portuguesa de Velimir Khlébnikov, levando-se em consideração todas as traduções coletadas de seus poemas até este momento (de tradutores como Aurora Bernardini, Marco Lucchesi, André Vallias, o autor deste artigo), há ainda um longo caminho a trilhar. Talvez, com benevolência, a quantidade traduzida alcance algo em torno de dez porcento da produção do poeta russo, considerado por Jakobson o mais importante poeta da primeira metade do século XX. 
Um dos aspectos mais relevantes da poética de Khlébnikov, no contexto do movimento cubofuturista, é a produção de poemas em série, nos quais aborda os mencionados diferentes métodos de criação em língua transmental, seja ao desdobrar neologismos a partir de um mesmo campo lexical utilizado em outros poemas, seja ao aplicar os métodos de criação a outras escolhas lexicais (o mesmo processo de repetição ocorre também em relação aos poemas de caráter fonético, às variações sintáticas, à elaboração de línguas aleatórias, especificamente criadas para representar as falas de deuses, animais ou estados emocionais, às pinturas sonoras - neologismos únicos, capazes de representar imagens ou conceitos novos e completos -, e outros métodos zaúm). O exemplo acima de “Encantação pelo Riso", na verdade, é fruto dessa característica, já iniciada a partir de experimentos que remontam a 1907, ou seja, em torno de cinco anos antes dos primeiros manifestos das vanguardas russas. Naquele ano, Khlébnikov criara, entre outros, um poema sem título bastante semelhante, porém no qual a base utilizada fora a palavra "amor" (любовь, liubov), cujo primeiro verso já indica a profusão de neologismos que se seguem nos sete seguintes: Я любоч, любимый любаной,” (Iá liubótch, liubimyi liubánoi), algo próximo a "Eu sou o amoradeiro, o amado fodamante" (Khlébnikov 2001). Outros poemas de Khlébnikov configuramse como verdadeiros glossários, dispostos verticalmente, com os neologismos ou, em outros casos, as pinturas-sonoras, as palavrasconceitos, apresentadas acompanhadas de breve explicação (em forma poética, livre) dos novos significados mais amplos que propunham. Trata-se, desse modo, da exposição de métodos que poderiam ser utilizados coletivamente pelo grupo de poetas e, além disso, de um tipo de sistematização da língua transmental, com o intuito de que pudesse ser adotada como uma nova língua, especificamente para uso poético.

Os resultados obtidos por Augusto e Haroldo de Campos e Boris Schnaiderman, no que diz respeito à transcriação dos métodos zaúm e à manutenção do "tom", do efeito original dos poemas em russo, como primeira experiência em língua portuguesa, possibili- 
tam aos tradutores posteriores de textos zaúm um diálogo no processo tradutório que pode garantir, além do plano da historicidade das traduções, a permanência ou fixação de certa familiaridade dos leitores com os autores russos já consagrados em nossa língua, ainda que em escassas seleções de poemas. Trata-se, então, de uma abordagem tradutória que prevê, a princípio, a continuidade e desenvolvimento das traduções anteriores e cristalizadas dos procedimentos zaúm, o que não exclui, de forma alguma, a retradução como crítica à tradução, tampouco exclui a perspectiva de inovação ao novo tradutor. Apenas é necessário atentar, dentro do macrocosmo dos procedimentos em língua zaúm, aos microelementos inovadores e distintos que surgem a cada novo poema ou texto em prosa.

Em 1921, Khlébnikov compõe Zanguézi, dentro de seus planos, já expostos em outros textos, de criar um novo tipo de épico, o qual denominou "supersaga". Nas supersagas, o poeta utiliza todos as possibilidades da língua zaúm, além de propor que, do ponto de vista do gênero, convivam poemas líricos, fragmentos em prosa literária ou ensaística e fragmentos em textos dramáticos. Trata-se, para Khlébnikov, da concepção de um novo gênero, plano que, caso não tivesse sido interrompido pela morte prematura do autor, em 1922, transportaria os microprocedimentos zaúm no campo da linguagem para o macroprocedimento no âmbito do gênero. Zanguézi é composto de diversos "planos" (em russo, Плоскость, Plóskost). No décimo plano, o herói da narrativa, o próprio Zanguézi, entra no "reino" da letra "M" (outro método de criação zaúm, segundo o qual determinada letra, associando aleatoriamente diversas palavras de diferentes sentidos, pode impulsionar a criação de grupos de neologismos). Surge, então, um novo herói para o novo épico, o "mogatyr", palavra baseada na fusão da forma radical "mog" (do verbo motch, poder), com o substantivo "bogatyr" (богатыр, denominação do mais famoso herói dos antigos épicos de tradição oral russos). Na tradução que aqui apresentamos, o reino da letra $\mathrm{M}$ transforma-se em reino da letra $\mathrm{P}$, para a associação com o verbo "poder" e outras associações com os adjetivos ligados ao campo 
lexical, como "poderoso", no original, o que torna o "mogatyr" de Khlébnikov no "poderói", em português. O processo de tradução envolveu a liberdade de criação de neologismos, na tentativa de responder às formas inusitadas do original, porém, foi bastante inspirado nas soluções obtidas por Haroldo de Campos em suas traduções, com o principal intuito de, ao mesmo tempo, acompanhar o efeito poético do original e manter a familiaridade do leitor com o tom já conseguido com sucesso em português. A expectativa é a de que, em nossa, a dicção de Khlébnikov seja imediatamente reconhecida, em associação com as traduções já consagradas.

Vai, poderói!

Marcha, poderói! Possarda, possardor!

Possaz, eu podo!

Poderudo, eu posso! Podei, eu podo!

Podei, meu eu. Prumado! Aprumado!

Podei, posseidor!

Poderandai, olhos! Prumados!

Aprumados!

Desfilai, podeidades!

Marcha, posseidor! Mãos! Mãos!

Possálico, podivinoso semblante, cheio de pondorações!

Poderardentes olhos, posselhonários pensares, pondereiros sobrolhos!

O rosto dos podentreiros. A mão dos podentreiros! Possenvasores!

Mãos, mãos!

Possublimes, possálicas, podivinas,

Portenteiras, potenciosas,

poderousadas!

Posserga-se, semblante!

Onipodentes, posserosas podeidades,

Vocês espalharam-se, cabelos, possindígenos,

Poderanos: poderdeiros, pelo

possenhor podivinoso, por podescendentes,

No meio dos possinfantes:
Иди, могатырь!

Шагай, могатырь! Можарь, можар!

Могун, я могею!

Моглец, я могу! Могей, я могею!

Могей, мое я. Мело! Умело! Могей, могач!

Моганствуйте, очи! Мело! Умело!

Шествуйте, моги!

Шагай, могач! Руки! Руки!

Могунный, можественный лик, полный могебнов!

Могровые очи, могатые мысли, могебные брови!

Лицо могды. Рука могды! Могна!

Руки, руки!

Могарные, можеские, могунные, Могесные, мошные, могивые!

Могесничай, лик!

Многомогейные, могистые моги, Это вы рассыпались, волосы, могиканами,

Могеичи - моговичи, можественным могом, могенятами, Среди моженят - могушищ, могеичей можных, 
o potentaço, dos poderozes

proverossímeis,

Enrosca-se um sapoderoso,

Possencantado por podivineiros

podencantos de possentes

posselhardários.

Na multidão de possinfantes e

poderdeiros.

Água no bico! As asas da gralha fazem ruído.

Tenho pressa, não posso atrasar!

O rosto, poderói! Possai, poderoz!

Podei, possaz!

Possereiro, possai!

Em poderardor, possincendeio com

potentochas o podereino!

Possereiro, possai! Podei, Possaz!

Vai, poderói!

Poderarde a podreria! O poderardor

do possincêndio!

O possencanto, potentante!

Possarda, minha mente! Possai, mãos!

Possejam, mãos!

Possaz, poderoz e poderói!
Вьется один могушонок,

Можбой можеству могес могатеев могатых.

В толпе моженят и моговичей.

Вода в клюве! Крылья шумят ворона.

Тороплюсь, не опоздать бы!

Лицо, могатырь! Могай, моган!

Могей, могун!

Могачь, могай!

Иду можарищем, можарю

можарство можелью!

Могачь, могай! Могей, могуй!

Иди, могатырь!

Мог моготы! Можар можавы!

Могесник, мощник!

Можарь, мой ум! Могай, рука!

Могуй, рука!

Моган, могун и могатырь!

(Francisco Jr. 94)

Não se trata, portanto, da retradução de um texto já traduzido, Zanguézi é inédito em português e a tradução não é baseada em um mesmo texto-fonte, nem da atualização de uma tradução "envelhecida" do original. Não deixa de ser, por outro lado, retradução, mas a retradução de um procedimento, de um método de criação utilizado em diferentes textos (às vezes, até de diferentes autores, de acordo com o caráter coletivos das vanguardas). As primeiras traduções servem como norteadoras das retraduções aqui apresentadas, em relação de continuidade, desenvolvimento e aprofundamento. O diálogo com os textos consagrados na língua de chegada torna-se uma via de mão dupla, processo de retroalimentação no qual a nova tradução aponta para a antiga, e vice-versa, o que busca possibilitar ao leitor não apenas ter acesso a um novo olhar 
tradutório de textos isolados que apresentem novos poemas de Khlébnikov em português, mas também "reconhecer" um Khlébnikov em língua portuguesa, imagem construída na interrelação entre poemas recriados por diferentes tradutores. A manutenção de traços da poética do autor original é tão importante, no caso, quanto a linha de continuidade de traços da poética resultante de suas primeiras traduções pelos irmãos Campos e Schnaiderman. Em decorrência desse objetivo maior, preferimos adotar para essa via, o termo cotradução:

Numa proposta radical, seria possível defender que falássemos não em retradução, termo que pode ser encerrado na perspectiva substitutiva, linear, cronológica, mas em cotradução: traduções, retraduções, (re)traduções que coexistem e convivem, seja em diálogo, em complementaridade, em dissonância - ou mesmo em ressonância. Evita-se uma perspectiva evolucionista e valoriza-se uma perspectiva sincrônica, que olha para as retraduções como releituras e reescrituras que, assim como qualquer material crítico, convivem em um mesmo espaço - nesse caso, o espaço da tradução, alargando-se, portanto, aquele 'espaço da tradução’ previsto por Berman. (Mattos and Faleiros 52)

O que chamamos acima de cotradução implica, também, o diálogo, a ressonância entre traduções como crítica. O método tradutório de Haroldo de Campos para a poesia zaúm responde diretamente a seu conceito de tradução como recriação, ou "criação paralela", na qual

traduz-se o próprio signo, ou seja, sua fisicalidade, sua materialidade mesma (propriedades sonoras, de imagética visual, enfim, tudo aquilo que forma, segundo Charles Morris, a iconicidade do signo estético, entendido por signo icônico aquele 'que é de certa maneira similar àquilo que ele denota'). O significado, o parâmetro semântico, será 
apenas e tão-somente a baliza demarcatória do lugar da empresa recriadora (Campos 35)

Em outro poema zaúm de Khlébnikov tornado conhecido por sua tradução por Augusto de Campos e Boris Schnaiderman em Poesia Russa Moderna, “Tempos-juncos” (poema de 1908-1909, também parte de uma pequena série de poemas), é notório o recuo em relação a todas as outras traduções do poeta na coletânea, no que diz respeito à recriação dos neologismos e transgressões sintáticas khlebnikovianas.

Tempos-juncos

$\mathrm{Na}$ margem do lago,

Onde as pedras são tempo,

Onde o tempo é de pedra.

No lago da margem,

Tempos, juncos,

$\mathrm{Na}$ margem do lago,

Santos, juntos.
Времыши-камыши

На озера береге,

Где каменья временем,

Где время каменьем.

На берега озере

Времыши, камыши,

На озера береге

Священно шумящие.

(Campos; Campos and Schnaiderman 117)

Logo no início do poema sem título, e que tem como tema principal a materialidade física (na representação imagética e na palavra) do tempo, o resultado do primeiro verso é o substantivo composto "tempos-juncos". Os elementos semânticos centrais estão ali, de fato: "tempos" (время, vrêmia) e "juncos" (камылии, kamychî). A palavra "vrêmia", porém, compõe sugerida aglutinação com outra (Mblub, mych, ou seja, "rato", mais precisamente, "camundongo"). Bem à maneira transmental de criação do poeta russo, a aglutinação cria outras possibilidades, como a própria absorção de parte da palavra kamychi (juncos), além de certa sugestão, nos dois finais "chi", de um suave diminutivo (o "i" final, nos dois casos, é nítida desinência de plural). Na via oposta, vremychi (traduzida como "tempos"), contamina o substantivo 
seguinte, transportando, por efeito inusitado do neologismo, nosso mych, camundongo, representação visual de algo pequeno ou ínfimo, para kamychí, o correspondente literal de "juncos". Apertando um pouco mais os olhos em nosso microscópio zaúm, no injusto conforto de nosso laboratório transmental, vemos que o terceiro verso traz a palavra "pedra" (камень, kamen) declinada, já essa, metade dela absorvida pelos tais "juncos" (novamente, kamychí). Tempos, juncos, o que é ínfimo, o que é eterno, a matéria, as pedras, o lago, o movimento, os sons, tudo está interligado na concepção de tempo khlebnikoviana. Apesar do aprofundamento profícuo dos tradutores nos neologismos de outros poemas do autor e de outros, a opção, no verso, foi pelo traço semântico central e mais convencional na composição do composto. O leitor brasileiro não tem acesso a nenhum rastro do efeito transgressor e provocativo original. Chama a atenção tal recuo, principalmente no caso de tradutores que lançaram mão de métodos de tradução inovadores com tantos poetas, russos ou não, e que propunham que

por meio da transcriação propõe-se recriar na língua de chegada, se não os efeitos iguais, ao menos efeitos similares ou análogos aos que se encontra na língua de partida. A transcriação é, além de crítica, também criativa. (Gessner 149)

Outra provocação zaúm bastante significativa e não considerada, seria a de ordem sintática, nos $2^{\circ}, 5^{\circ}$ e $7^{\circ}$ versos. No segundo verso, há um estranhamento de ordem sintática em На озера береге (Na ózera béregue, literalmente, "Na do lago margem”). O resultado final, como em sua repetição no sétimo verso, mantem a ordem sintática direta e convencional "Na margem do lago". $\mathrm{O}$ estranhamento se dá por conta do afastamento entre a preposição russa "na" (o mesmo em português, nesse caso) e béregue, a "margem” em caso prepositivo. As duas estão intercaladas por ózero, o "lago", declinada em genitivo. O mesmo ocorre no quinto verso, 
Hа берега озере (Na beregá ózere, literalmente, "No da margem lago"), que recebe a tradução "No lago da margem". Tais inversões de posições são permitidas em língua russa, em decorrência de suas características sintáticas, mas certamente não são construções usuais. O embaralhamento dos elementos sintáticos e suas inversões de posições nos versos contribuem para a concepção de unidade total entre tempo e espaço, matéria, palavras e, por fim, estruturas da língua. O verso final, em forma mais tradicional, conduz as aliterações à representação do som do vento nos juncos, ou do movimento da água na margem do lago, Свящзенно шумящие (Sviaschénno Chumiáschie, em português literal, "sagrados ruidosos", ou, se quisermos "sibilantes sagrados"), com profusão alternada de "s" e "ch". Os tradutores mantiveram o recurso dos "s" para a expressão sonora do verso, e recuperaram a relação por similaridade entre "juntos" e "juncos". Mas os recursos baseados em neologismos e estranhamentos sintáticos, em geral, desaparecem, ainda que o resultado não deixe de soar como um bom poema em português.

No mesmo período, 1907 ou 1908 (não há datação específica), Khlébnikov compôs outro poema curto, que pode ser relacionado diretamente com "tempos-juncos”, pois a mesma dupla de substantivos é novamente explorada, na formação de novos neologismos, agora com a associação entre "tempos" e "juncos" com seres animados, que podem ser identificados como pássaros ou seres imaginários.

Quando em pasárgada passavam

Rápidos bandos de tempássaros,

Com tempos-juncos eu brincava,

Tempículos-júnculos lançava,

Tempilhos-junquilhos laçava,

E uma tempríria abria as asas.
В пору, когда в вырей

Времирей умчались стаи,

Я времушком-камушком игрывало,

И времушек-камушек кинуло,

И времушко-камушко кануло,

И времыня крылья простерла.

(Francisco Jr 06) 
O "adensamento das ligações semânticas" intratextuais e extratextuais é um dos fatores intrínsecos à linguagem poética mais discutidos entre teóricos da literatura russa, no estudo da poesia, desde Aleksandr Potebniá, no século XIX, a Iúri Lotman, no século XX (Américo 25). Este último via no adensamento das ligações semânticas um dos fatores de maior complexidade para a tradução poética, ainda que consideremos a poesia "tradicional". Na poesia que utiliza a língua transmental, em poemas líricos concisos, a expansão das capacidades semânticas em elementos mínimos, como neologismos, torna sua "massa" extremamente densa e, sob a inspiração das concepções de tempo de Khlébnikov, capaz de provocar, por sua enorme gravidade, curvaturas no espaço-tempo (a título de curiosidade, Khlébnikov, também matemático, adotava uma abordagem filosófica do tempo muito próxima à do filósofo alemão G. W. Leibniz).

Na tradução do outro poema da série "Tempos-juncos” acima apresentada, em que o eu entra no jogo e "brinca" com o "tempo", buscamos considerar, no processo de tradução, os elementos intratextuais característicos da poética de Khlébnikov e um pequeno "recuo" que aponta, em cotradução, para a recriação poética de Augusto de Campos e Bóris Schnaiderman. Os neologismos surgidos no poema "tempos-juncos" são desenvolvidos, ou desdobrados, neste último, para vremiréi, vremuchkom-kamuchkom, vremuchek-kamuchek, vremuchka-kamuchka, vremyniá. Quase todos os compostos formam neologismos com sentido diminutivo (por inserção de sufixos), com o primeiro e o último, contextualmente, estabelecendo unidade entre o tempo e animais. No quarto e no quinto versos, ao espírito khlebnikovaroldiano, as traduções resultam também em neologismos de sentido diminutivo, como em "tempículos-júnculos" e "tempilhos-junquilhos". O mesmo não ocorreu com o terceiro verso, primeira referência aos "tempos-juncos" do poema anterior. O recuo diante da opção por uma terceira forma diminutiva de neologismo deve-se à intenção de referência imediata à tradução consagrada de "tempos-juncos", numa relação dialógica entre traduções, ou numa cotradução, que tem o intuito de integrar os dois 
poemas na mesma série em que estão associados originalmente. A sintaxe mantem-se simples, direta, como algumas rimas entre verbos, reproduzindo a sintaxe original, que guarda certo tom de infantilismo típico da poética de Khlébnikov e condizente com as ações do eu no poema.

A retradução, ou cotradução, como preferimos, funciona em diferentes vetores. O diálogo criativo com as traduções anteriores dá suporte à sistematização da língua transmental em português, como fora elaborada pelos poetas da vanguarda russa. Trata-se da cotradução de um procedimento, e não de textos específicos. Permite também o agrupamento de poemas que originalmente foram criados em séries, como afirmamos acima, e, numa perspectiva mais ampla, possibilita a recuperação do tom, da dicção próprios à poética do autor na língua de chegada, um trabalho de diferentes tradutores, em diferentes momentos, mas cujos resultados podem convergir em uma mesma direção, num mesmo ponto.

\section{Referências}

Américo, E. V. "O conceito de tradução na obra de Iúri Lotman: entre intraduzibilidade e liberdade". Tradterm. São Paulo, v. 24 (2014): 17-33. Portal de Periódicos da USP. http://www.revistas.usp.br/tradterm/article/view/96128

Campos, H. "Da Tradução como Criação e como Crítica". In: Campos, H. Metalinguagem e outras metas. São Paulo: Perspectiva, 2004.

Campos, A., Campos, H. e Schnaiderman, B. (org.). Poesia Russa Moderna. $6^{\mathrm{a}}$ ed. rev. e ampl. São Paulo: Perspectiva, 2001.

Krutchônikh, A. "Manifest iz sbórnika "Sadók Sudiéi II". < http://rozanova.net/ second_page.pl?id $=411 \&$ catid $=14>$. 
Francisco Jr., M.R. "Velimir Khlébnikov: o mago do além-sentido". Revista Coyote, Londrina, n. 26. Kan Editora, 2014.

Francisco Jr., M.R. Zanguézi, de Velimir Khlébnikov: a utopia da obra de arte como síntese perfeita do universo. Tese (Doutorado em Literatura e Cultura Russa), Faculdade de Filosofia, Letras e Ciências Humanas, Universidade de São Paulo. São Paulo, 2007.

Gessner, R. “Transcriação, transconceituação e poesia”. Cadernos de Tradução. Florianópolis, v. 36. n. 2 (2016): 142-162. Portal de Periódicos da UFSC. https:// periodicos.ufsc.br/index.php/traducao/article/view/2175-7968.2016v36n2p142.

Khlébnikov, V. Sobránie Sotchiniénii v Triôkh Tomakh - Tom Piérvyi Stikhotvoriénia. São Petersburgo: Akademítcheskii Proekt, 2001.

Maiakóvski, V. "V. V, Khliébnikov". In: Schnaiderman, Boris (Org). A Poética de Maiakóvski. São Paulo: Perspectiva, 1971.

Mattos, T. e Faleiros, A. “A noção de retradução nos estudos da tradução: um percurso teórico". Revista Letras Raras. Campina Grande, Vol. 3. n. 2 (2014): 35-57. Portal de Periódicos da UFCG. http://revistas.ufcg.edu.br/ch/index.php/ RLR/article/view/307.

Menezes, P. Poesia Sonora - Poéticas experimentais da voz no século XX. São Paulo: Educ, 1992.

Schnaiderman, B. Tradução, Ato Desmedido. São Paulo: Perspectiva, 2011.

Recebido em: 05/04/2019

Aceito em: 27/06/2019

Publicado em dezembro de 2019

Mario Ramos Francisco Junior. E-mail: mariofrancisco@usp.br

ORCID: https://orcid.org/0000-0002-3277-9341 